\title{
Anticorrosive Effect of PVP 40000 Against AISI 1020 Carbon Steel in HCl
}

\author{
Arthur Valbon ${ }^{a}$, Marcelo Azevedo Neves $^{b}$, Aurea Echevarria $^{a} *$ (D) \\ ${ }^{a}$ Departamento de Química, Instituto de Ciências Exatas, Universidade Federal Rural do Rio de \\ Janeiro, BR 465, km 07, 23840-000, Seropédica, RJ, Brasil \\ ${ }^{b}$ Departamento de Física, Instituto de Ciencias Exatas, Universidade Federal Rural do Rio de Janeiro, \\ BR 465, km 07, 23840-000, Seropédica, RJ, Brasil
}

Received: September 22, 2017; Revised: March 07, 2018; Accepted: June 28, 2018

\begin{abstract}
Polymers have received considerable attention for replacing synthetic inorganic and organic anti-corrosion inhibitors since they are not as toxic for the environment, besides being cheaper. Polyvinylpyrrolidone (PVP) has been studied due to its applicability, solubility, very low toxicity, cost and efficiency in corrosion inhibition against metals, such as zinc, aluminum, stainless steel, and others. Its anti-corrosion activity with $40000 \mathrm{~g} \mathrm{~mol}^{-1}$ was tested against AISI 1020 carbon steel in $0.5 \mathrm{~mol} \mathrm{~L}^{-1} \mathrm{HCl}$, and evaluated by electrochemical techniques: Potentiodynamic Polarization (PP), Linear Polarization Resistance (LPR), and Electrochemical Impedance Spectroscopy (EIS). The maximum efficiency was $90 \%$ and $89 \%$ in EIS and LPR, respectively, at concentration of $1.0 \times 10^{-7}$ mol L-1. The adsorption mechanism was coherent with Langmuir isotherm model. The morphology of the corroding carbon steel surface, in the presence and absence of the PVP, was visualized using Scanning Electron Microscopy (SEM).
\end{abstract}

Keywords: Polyvinylpyrrolidone, Anticorrosive, Potentiodynamic Polarization, Electrochemical Impedance Spectroscopy, Scanning Electron Microscopy.

\section{Introduction}

Mild steel is widely used in a diversity of industries, such as chemical processing, petroleum production and refining, and marine applications, including the exposure in acidic media for pickling, and in saline media in the case of offshore operations. However, the deterioration of mild steel must be attenuated by various anticorrosive agents, including organic corrosion inhibitors. Organic compounds containing heteroatoms in their structure, such as nitrogen, oxygen and sulfur, are able to act as efficient inhibitors for some metals since they can form protective films on the surface ${ }^{1-3}$. The use of polymers in solution as corrosion inhibitors has been widely studied in the last years, due to its low cost and good inhibition efficiency ${ }^{1-6}$.

Recently, green corrosion inhibitors have been receiving special attention for the replacement of synthetic inorganic and organic substances with high environmental toxicity, at very expensive cost. Several polymers were investigated years ago, including the polyvinylpyrrolidone (PVP) due to its easy applicability, solubility, very low toxicity, cost and corrosion inhibition efficiency ${ }^{3}$. There are many studies involving the corrosion inhibition of several metals in solution, such as zinc, iron, carbon steel and stainless steel.

In 1985, Mostafa et al. described the efficiency of PVP 1000, PVP 24500 and PVP 40000 as corrosion inhibitors of zinc in $1 \mathrm{~mol} \mathrm{~L}^{-1} \mathrm{H}_{2} \mathrm{SO}_{4}$; the inhibition efficiency was $91 \%$,
$86 \%$ and $84 \%$, respectively, at PVP concentration of $0.1 \mathrm{~mol}$ $\mathrm{L}^{-17}$. In 1995, Janguo \& Schweinsberg studied PVP 10000 in $7.0 \mathrm{~mol} \mathrm{~L}^{-1} \mathrm{H}_{3} \mathrm{PO}_{4}$ against carbon steel with a maximum efficiency of $89 \%$ at $5.0 \times 10^{-5} \mathrm{~mol} \mathrm{~L}^{-18}$. PVP 10000 and PVP 45000 were investigated by Khaled, 2010, in 316L stainless steel in water containing $1 \mathrm{mg} \mathrm{L}^{-1} \mathrm{FeCl}_{3}$ and drops of $\mathrm{H}_{2} \mathrm{SO}_{4}$; $42 \%\left(1.0 \times 10^{-2} \mathrm{~mol} \mathrm{~L}^{-1}\right)$ and $96.7 \%\left(5.0 \times 10^{-3} \mathrm{~mol} \mathrm{~L}^{-1}\right)$ of corrosion inhibition was observed, respectively ${ }^{9}$.

Corrosion inhibition of carbon steel was also studied by Umoren, 2011, who used PVP $44000\left(1.0 \times 10^{-4} \mathrm{~mol} \mathrm{~L}^{-1}\right)$ in $0.5 \mathrm{~mol} \mathrm{~L}^{-1} \mathrm{H}_{2} \mathrm{SO}_{4}$, thus observing inhibition efficiency of $67 \%{ }^{10}$. Al Juhaiman et al., 2012, reported the anticorrosion efficiency of PVP 8000 in $2.5 \times 10^{-4} \mathrm{~mol} \mathrm{~L}^{-1}$ against carbon steel in $0.1 \mathrm{~mol} \mathrm{~L}^{-1} \mathrm{NaCl} ; 44 \%$ was the maximum efficiency ${ }^{2}$. The most recent study about PVP 8000 as an anti-corrosion agent against carbon steel has been done by Al Juhaiman, 2016, in $2 \mathrm{~mol} \mathrm{~L}^{-1} \mathrm{HCl}$ showing a maximum efficiency of $89.5 \%$ in $1.0 \times 10^{-3} \mathrm{~mol} \mathrm{~L}^{-14}$.

Given the great interest in the study of PVP as an anticorrosion agent, and the lack of information on middle steel in $\mathrm{HCl}$ medium, this paper aims to describe the study of PVP 40000 against AISI 1020 carbon steel in $0.5 \mathrm{~mol} \mathrm{~L}^{-1} \mathrm{HCl}$, using electrochemical techniques, like Potentiodynamic Polarization (PP), Linear Polarization Resistance (LPR) and Electrochemical Impedance Spectroscopy (EIS). Moreover, the scanning electron microscopy (SEM) was used to investigate anti-corrosion activity. 


\section{Experimental}

\subsection{Materials}

Polyvinylpyrrolidone (PVP) was purchased from Sigma Aldrich Co., and its molecular weight was 40000 g.mol ${ }^{-1}$. PVP chemical structure can be observed in Figure 1. Ethanol used as solvent was purchased from Vetec/Sigma-Aldrich (Rio de Janeiro, Brazil), and hydrochloric acid, from Proquimios Com. \& Ind. Ltda. (Rio de Janeiro, Brazil).

Tests were carried out with a conventional electrochemical three-electrode cell, which consists of a platinum auxiliary electrode, a silver-silver chloride $\left(\mathrm{Ag} / \mathrm{AgCl}, 3.0 \mathrm{~mol} \mathrm{~L}^{-1} \mathrm{KCl}\right)$ reference electrode, and the AISI 1020 carbon steel used as a working electrode with composition (\%wt): C: $0.17, \mathrm{P}$ : $0.04, \mathrm{~S}: 0.05, \mathrm{Mn}: 0.30$, and the remainder Fe. The working electrode was prepared with epoxy resin that presented an exposed area of $0.8 \mathrm{~cm}^{2}$. Before each measurement, the working electrode was abrading using three emery papers with different grades: 400, 600 and 1200. After that, it was washed with water and acetone and dried ${ }^{11}$.

\subsection{Blank and PVP solutions}

Blank was prepared at $0.5 \mathrm{~mol} \mathrm{~L}^{-1} \mathrm{HCl}$ aqueous solution using Milli-Q water. Five PVP solutions were prepared with different concentrations: $1.0 \times 10^{-7}, 5.0 \times 10^{-8}, 2.5 \times 10^{-8}, 5.0 \times 10^{-9}$, $1.0 \times 10^{-9} \mathrm{~mol} \mathrm{~L}^{-1}$, in the presence of $0.5 \mathrm{~mol} \mathrm{~L}^{-1} \mathrm{HCl}$.

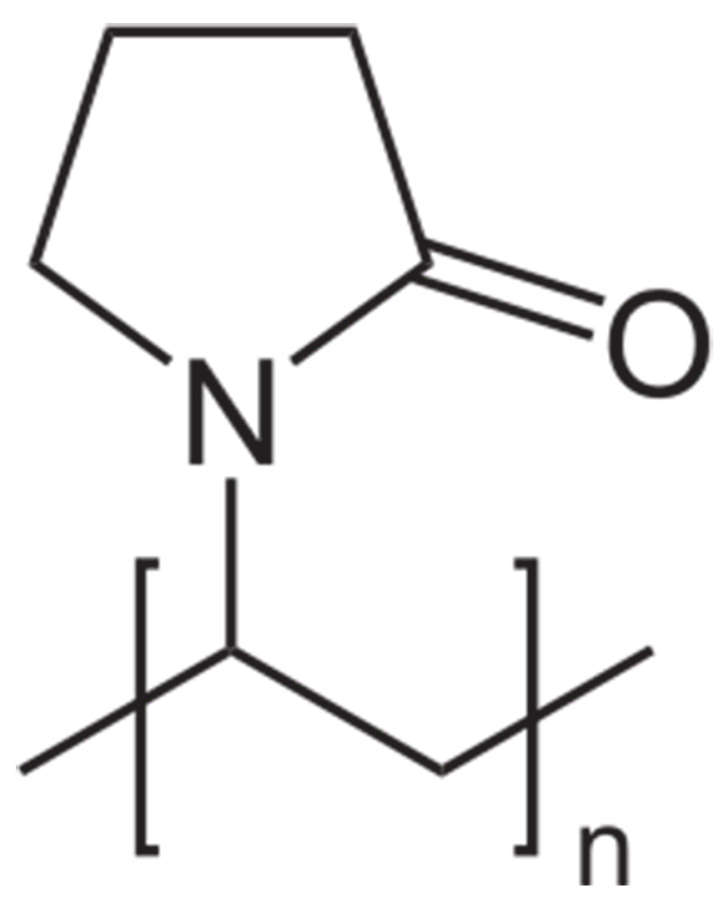

\subsection{Electrochemical procedure}

All experiments were carried out in $40 \mathrm{~mL}$ solutions of naturally aerated electrolyte at $25^{\circ} \mathrm{C}$, and all electrochemical measurements were performed using an Autolab Potentiostat/ Galvanostat model PGSTAT 302N, and analyzed using NOVA 1.9 software. The electrochemical measurements were conducted after $1 \mathrm{~h}$ immersion in experimental solution to attain a stable open circuit potential (OCP). After that, three electrochemical techniques were applied: Electrochemical Impedance Spectroscopy (EIS), Linear Polarization Resistance (LPR), and Potentiodynamic Polarization (PP).

\subsubsection{Electrochemical Impedance Spectroscopy (EIS)}

Impedance measurements were performed over a frequency range of $10 \mathrm{kHz}-100 \mathrm{mHz}$ with a $10 \mathrm{mV}$ peak-to-peak amplitude using AC signal. Inhibition efficiency (IE) was calculated using the following equation ${ }^{12}$ :

$$
I E_{E I S}=\frac{R_{c t}-R_{c t}^{0}}{R_{c t}} \times 100
$$

where $R_{\mathrm{ct}}$ is the charge transfer resistance in the presence of the inhibitor, and $R_{\text {ct }}^{0}$ is the charge transfer resistance in its absence. These values were obtained from the electrochemical impedance diagrams.

\subsubsection{Linear Polarization Resistance (LPR)}

Linear Polarization Resistance experiments were performed using a scan rate of $1 \mathrm{mV} \mathrm{s}^{-1}$ in the potential range of \pm $10 \mathrm{mV}$, around the open circuit potential $\left(E_{\text {ocp }}\right)$. Inhibition efficiency was calculated using the following equation ${ }^{12-16}$ :

$$
I E_{L P R}=\frac{R_{p}-R_{p}^{0}}{R_{p}} \times 100
$$

where $R_{\mathrm{p}}$ and $R_{\mathrm{p}}^{0}$ are the Polarization Resistance in the presence and absence of the inhibitor, respectively. The Polarization Resistance was obtained by the following equation:

$$
R_{p}=\frac{\Delta E}{\Delta i}
$$

These values were determined by the graph of the current (i) vs the potential $(E)$, where $R_{\mathrm{p}}$ is the slope of the line.

\subsubsection{Potentiodynamic Polarization (PP)}

Potentiodynamic anodic and cathodic polarization curves were performed using a scan rate equal to $1 \mathrm{mV} \mathrm{s}^{-1}$, from $-200 \mathrm{mV}$ up to $+200 \mathrm{mV}$, around the open circuit potential. Inhibition efficiency was calculated using the following equation ${ }^{12-16}$ :

$$
I E_{p p}=\frac{i_{\text {corr }, 0}-i_{\text {corr }}}{i_{\text {corr }, 0}} \times 100
$$

Figure 1. PVP chemical structure. 
where $i_{\text {corr }, 0}$ and $i_{\text {corr }}$ are the Polarization Resistance in the absence and presence of the inhibitor, respectively.

\section{Surface Analysis}

\subsection{Scanning Electron Microscopy (SEM)}

Carbon steel samples, dimension $4 \mathrm{~cm} \times 4 \mathrm{~cm} \times 0.1 \mathrm{~cm}$, were abraded with 280,600 and 1200 grade emery paper; washed with water and ethanol; dried and immersed in 0.5 mol L-1 $\mathrm{HCl}$ in the absence (Blank) and presence of PVP 40000 for $3 \mathrm{~h}$ at room temperature; and, naturally aerated. The specimens were removed, washed with water, ethanol, dried and weighted in analytical balance (SHIMADZU, model ATX224). The measurements were taken using HITACHI TM 3000 Tabletop Microscope ${ }^{16}$.

\section{Results and Discussion}

\subsection{Open Circuit Potential}

The OCP plots can be observed in Fig 2, the OCP values were stabilized after 40 minutes, but OCP was measured until 60 minutes. After the OCP stabilized, the EIS, LPR and PP tests were carreid out against carbon steel AISI 1020 in $\mathrm{HCl}$ $0.5 \mathrm{~mol} \mathrm{~L}^{-1}$ in the presence and absence of PVP.

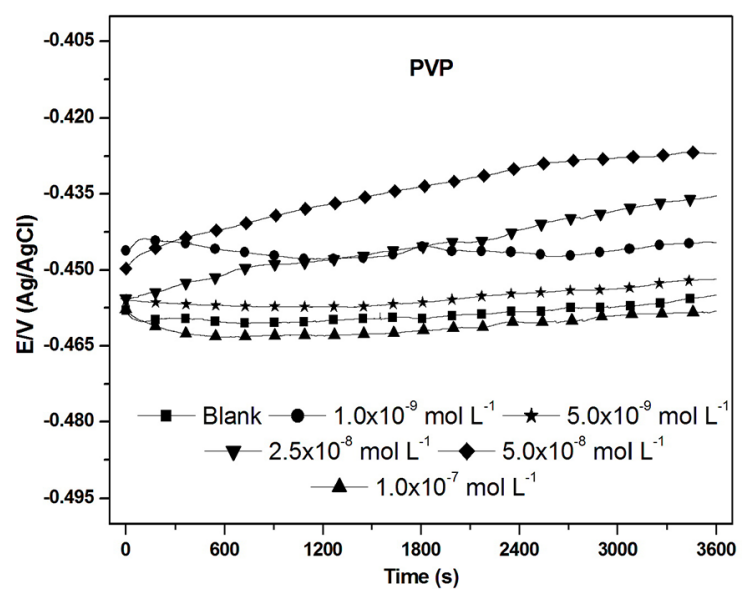

Figure 2. OCP plots of carbon steel obtained in $\mathrm{HCl} 0.5 \mathrm{~mol} \mathrm{~L}^{-1}$ in the presence and absence of PVP.

\subsection{Potentiodynamic Polarization (PP)}

Figure 3 presents the Potentiodynamic Polarization curves of carbon steel in $0.5 \mathrm{~mol} \mathrm{~L}^{-1} \mathrm{HCl}$ solutions, with and without PVP 40000, at five concentrations; they determined the values to plot the graphs of $\log i$ versus $E$. At that stage, the Potentiodynamic Polarization technique was used so that the behaviour of the current density, in the presence and absence of the inhibitor, could be observed and the inhibitor type could be characterized.

As observed in Figure 3, there is a decrease in the current density $(i)$ when PVP concentration increases in the cathodic region, and more remarkably, in the anodic one; with a great $E_{\text {corr }}$ shift in the anodic direction. These results indicate that PVP 40000 acted as a mixed-type inhibitor, which could slow down both the metal dissolution and the cathodic process ${ }^{16}$. The electrochemical parameters are shown in Table 1.

\subsection{Linear polarization resistance (LPR)}

Linear Polarization Resistance to carbon steel in $\mathrm{HCl} 0.5$ $\mathrm{mol} \mathrm{L}^{-1}$ were evaluated in the presence and in the absence of PVP 40000. Equation 3 shows the graph of values obtained for the current density $(i)$ versus applied potential $(E)$, which provided the slope of the lines corresponding to $R_{\mathrm{p}}$ values by linear regression. Table 2 shows the values of $R_{\mathrm{p}}$ and of

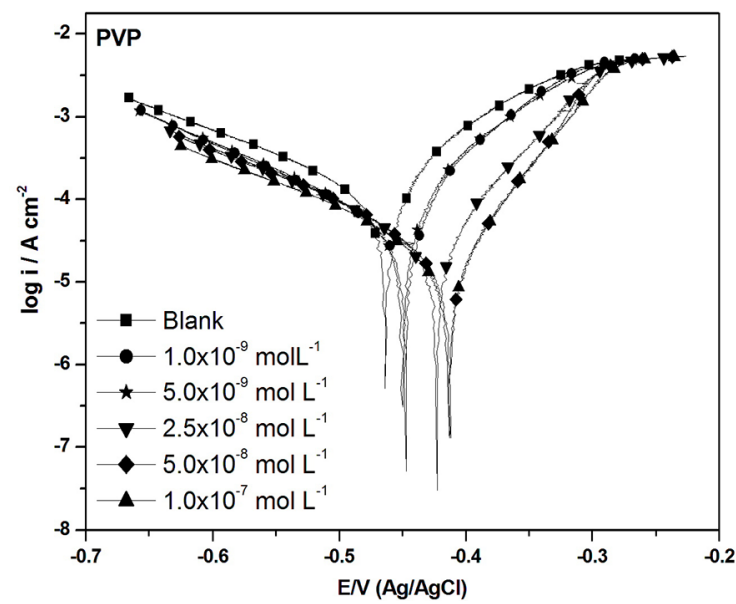

Figure 3. Polarization curves of carbon steel in $0.5 \mathrm{~mol} \mathrm{~L}^{-1} \mathrm{HCl}$ in the presence and absence of PVP.

Table 1. Electrochemical parameters obtained from Tafel plots for carbon steel AISI 1020, in $0.5 \mathrm{~mol} \mathrm{~L}^{-1} \mathrm{HCl}$ in the presence and absence of different PVP concentrations.

\begin{tabular}{|c|c|c|c|c|c|c|c|}
\hline Inhibitor & $\boldsymbol{C}_{i n h}\left(\mathrm{~mol} \mathrm{~L}^{-1}\right)$ & $\begin{array}{l}\boldsymbol{E}_{\text {corr }} \mathrm{vs} . \mathrm{Ag} / \\
\mathrm{AgCl}(\mathrm{mV})\end{array}$ & $\boldsymbol{j}_{\text {corr }}\left(\mathrm{mA} \mathrm{cm}^{-2}\right)$ & $\boldsymbol{\beta} \mathrm{a}\left(\mathrm{mV} \mathrm{dec}{ }^{-1}\right)$ & $\left.-\beta \mathrm{cmV} \mathrm{dec}^{-1}\right)$ & $\theta$ & $\boldsymbol{I} \boldsymbol{E}_{P P}(\%)$ \\
\hline \multirow[t]{3}{*}{ Blank } & - & -464 & 0.165 & 205 & 76 & - & - \\
\hline & $1.0 \times 10^{-9}$ & -449 & 0.069 & 147 & 47 & 0.58 & 58 \\
\hline & $5.0 \times 10^{-9}$ & -451 & 0.061 & 147 & 51 & 0.63 & 63 \\
\hline \multirow[t]{3}{*}{ PVP } & $2.5 \times 10^{-8}$ & -424 & 0.038 & 160 & 61 & 0.77 & 77 \\
\hline & $5.0 \times 10^{-8}$ & -413 & 0.019 & 106 & 51 & 0.88 & 88 \\
\hline & $1.0 \times 10^{-7}$ & -414 & 0.018 & 116 & 52 & 0.89 & 89 \\
\hline
\end{tabular}


the anti-corrosion efficiency $\left(I E_{\mathrm{LPR}}\right)$, thus demonstrating how the slope increases when the inhibitor concentration rises.

\subsection{Electrochemical impedance spectroscopy}

Figure 4 shows the Nyquist plots related to the measurements made on carbon steel in acid media $0.5 \mathrm{~mol} \mathrm{~L}^{-1} \mathrm{HCl}$, in the presence and the absence of PVP at different concentrations The fitted curves obtained by the $[R(R Q)]$ circuit can also be observed in the Figure 4. As shown in Figure 4, the semicircle increases along with the concentration, thus resulting in the rise of the inhibition efficiency. This indicates that the corrosion of carbon steel in acidic medium is controlled by a charge-transfer process ${ }^{8}$.

The intersection of the semicircle and the real axis at high frequencies provides the solution resistance $\left(R_{\mathrm{s}}\right)$ value, whereas at low frequencies, a charge-transfer resistance $\left(R_{\mathrm{ct}}\right)$ was found from the difference in impedance at lower and higher frequencies.

According to the above results, the EIS data were analyzed using the $[R(R Q)]$ equivalent circuit (Fig. 5) that includes

Table 2. Electrochemical parameters obtained from LPR measurements for carbon steel, in the presence and the absence of different PVP 40000 concentrations, in $0.5 \mathrm{~mol} \mathrm{~L}^{-1} \mathrm{HCl}$.

\begin{tabular}{lcccc}
\hline Inhibitor & $\begin{array}{c}\boldsymbol{C}_{i n h}(\mathrm{~mol} \\
\left.\mathrm{L}^{-1}\right)\end{array}$ & $\boldsymbol{R}_{p}\left(\Omega \mathrm{cm}^{2}\right)$ & $\boldsymbol{\theta}$ & $\boldsymbol{I E}_{L P R}(\%)$ \\
\hline Blank & - & 190.49 & - & - \\
& $1.0 \times 10^{-9}$ & 452.94 & 0.5794 & 58 \\
& $5.0 \times 10^{-9}$ & 450.00 & 0.5767 & 58 \\
PVP & $2.5 \times 10^{-8}$ & 815.11 & 0.7663 & 77 \\
& $5.0 \times 10^{-8}$ & 1533.50 & 0.8758 & 88 \\
& $1.0 \times 10^{-7}$ & 1733.00 & 0.8901 & 89 \\
\hline
\end{tabular}
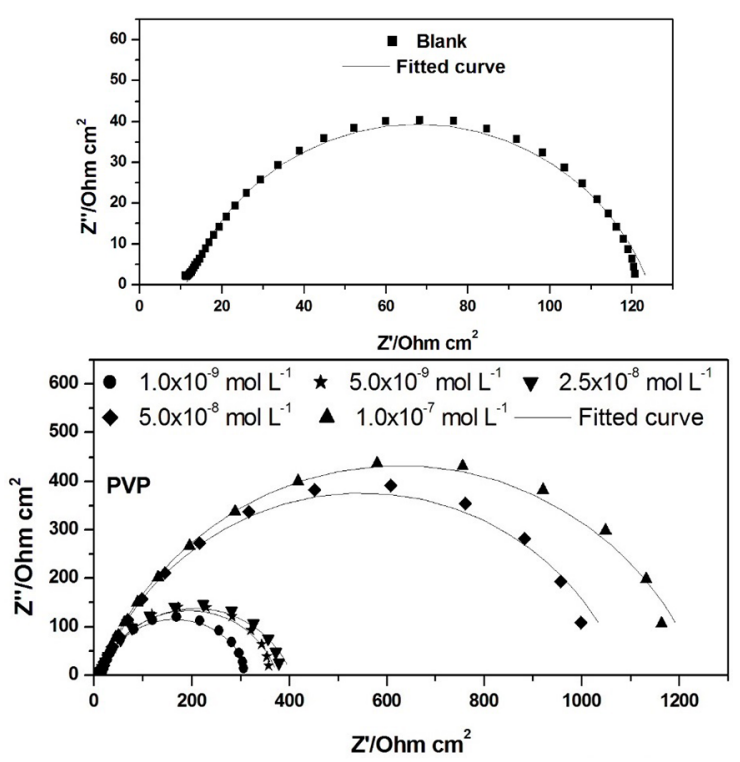

Figure 4. Nyquist plots of carbon steel obtained in $\mathrm{HCl} 0.5 \mathrm{~mol}$ $\mathrm{L}^{-1}$, in the blank and in the presence of PVP 40000. the solution resistance $(R)$, polarization resistance $\left(R_{\mathrm{p}}\right)$ and constant phase element (CPE), which can be represented in equation $5^{13,14,15}$ :

$$
Z_{C P E}=Y_{0}^{-1}(j w)^{-n}
$$

where $Y_{0}$ is the magnitude of the CPE, $n$ is the phase shift, $\mathrm{j}$ is the imaginary unit and $w$ is the angular frequency. The constant phase element, CPE, was introduced in the circuit instead of a pure double layer capacitor to give a more accurate fit ${ }^{16-19}$.

The double layer capacitances, $C_{\mathrm{dl}}$, for a circuit including a CPE were calculated from the following equation $6^{17-20}$ :

$$
C_{d l}=Y_{0}\left(2 \pi f_{\max }\right)^{n-1}
$$

where $Y_{0}$ is the magnitude of the CPE, $f_{\max }$ is the frequency at which the imaginary component of the impedance is maximal ${ }^{17-20}$.

The increase of $R_{\mathrm{ct}}$ and the decrease of $C_{\mathrm{dl}}$ indicates that PVP inhibits the corrosion rate of carbon steel by adsorption mechanisms ${ }^{19}$. The equivalent circuit fit (Figure 5) was obtained by EIS spectra.

Bode plots for carbon steel in acidic medium with and without PVP are shown in Figure 6. At low frequencies,

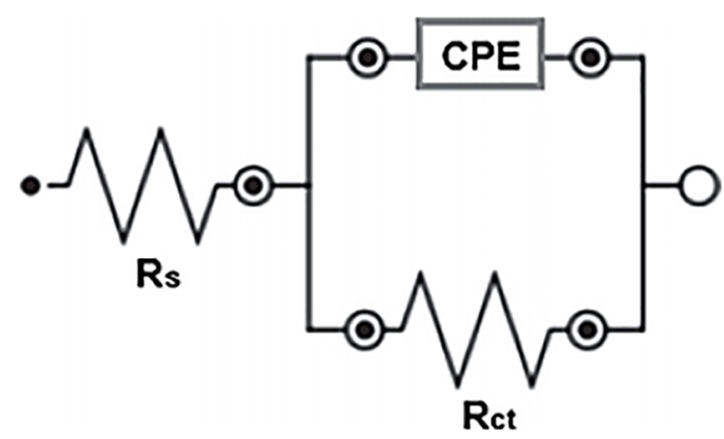

Figure 5. Equivalent circuit model used to fit EIS experimental data, in the presence and the absence of PVP.

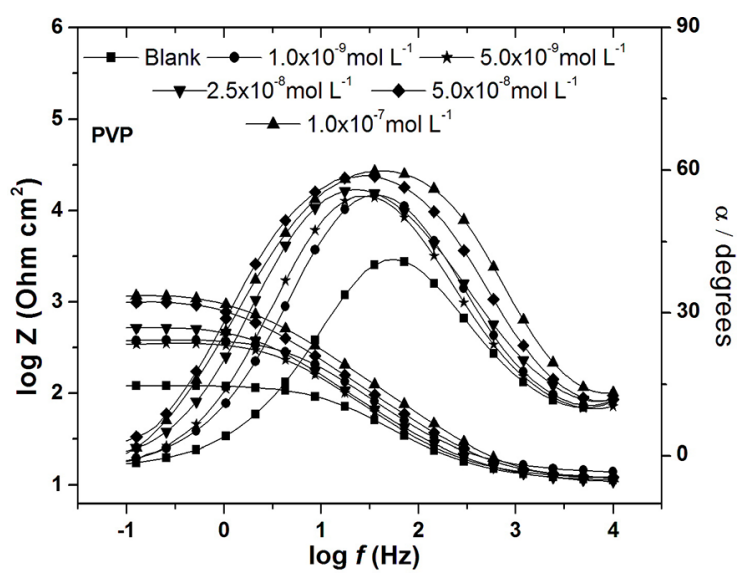

Figure 6. Bode plots of carbon steel obtained in $0.5 \mathrm{~mol} \mathrm{~L}^{-1} \mathrm{HCl}$, in the presence and the absence of PVP. 
$Z_{\text {mod }}$ is a metric that can be used to compare the corrosion resistance at different concentrations of inhibitor, and its increase contributes to a better inhibitory performance ${ }^{16,19}$.

Table 3 shows the values of corrosion inhibition efficiency $\left(I E_{\mathrm{EIS}}\right)$, resistance of charge-transfer $\left(R_{\mathrm{ct}}\right)$, inhibitor surface coverage $(\theta)$ and double layer capacitance $\left(C_{\mathrm{d} 1}\right)$.

In Table 3, it is noteworthy that the efficiency increases when the PVP concentration rises. An efficiency of $90 \%$ was observed at the concentration of $1.0 \times 10^{-7} \mathrm{~mol} \mathrm{~L}^{-1}$ by EIS. The lowest $C_{\mathrm{dl}}$ value is observed at the maximum concentration of PVP; this can be associated with a better adsorption of the inhibitor in metallic surface, thus leading to the decrease of the electric double layer.

It is important to highlight that $n_{\text {LPR }}$ values obtained from LPR presented correlation with the values obtained by the EIS measurement $\left(I E_{\mathrm{EIS}}\right)$, in which the efficiency increase was observed along with the increase of PVP concentration, $89 \%$ and $90 \%$ at $1.0 \times 10^{-7} \mathrm{~mol} \mathrm{~L}^{-1}$ for $I E_{\mathrm{EIS}}$ and $I E_{\mathrm{LPR}}$, respectively.

\subsection{Adsorption isotherm}

PVP adsorption mechanism over a metal surface was investigated, and the most frequent one was modelled by Langmuir equation $(7)^{11,16,19}$. Figure 7 shows the plot for Langmuir isotherm model.

$$
\frac{C_{i n h}}{\theta}=\frac{1}{K_{a d s}}+C_{i n h}
$$

where $C_{\text {inh }}$ is the inhibitor concentration, $\theta$ is the degree of surface coverage and $K_{\text {ads }}$ is the adsorption equilibrium constant. The standard free energy of adsorption $\left(\Delta G\left(\begin{array}{ll}0 & 0 \\ \text { ads ads }\end{array}\right)\right.$ was calculated by equation $8^{11}$.

$$
\Delta G_{a d s}^{0}=-R T \ln (55.55) K_{a d s}
$$

where $R$ is the universal gas constant $\left(8.31 \mathrm{~J} \mathrm{~K}^{-1} \mathrm{~mol}^{-1}\right), T$ is the temperature $(\mathrm{K})$, and 55.55 is the molar concentration $(\mathrm{mol} \mathrm{L}-1)$ of water in the solution.

The thermodynamic parameters obtained in this study indicated $K_{\text {ads }}=2.32 \times 10^{+9} \mathrm{~L} \mathrm{~mol}^{-1}$ and $\Delta G_{\text {ads }}^{0}=-59.18 \mathrm{~kJ}$ $\mathrm{mol}^{-1}$. The slope (1.09) and the linear correlation coefficient (0.9993) were close to one, thus characterizing the Langmuir isotherm model ${ }^{11,16,21-24}$.
The negative value of free energy of adsorption revealed the spontaneity of its process; also, the higher the adsorption equilibrium constant, the more stable the adsorbed layer on the steel surface. The Langmuir isotherm describes that each inhibitor molecule is adsorbed on a distinct steel surface site; therefore, an adsorbed water molecule is replaced by an organic molecule on the steel surface. The adsorption of organic molecules occurs as a monolayer over the metallic surface without any interaction with other adsorbed molecules ${ }^{18,19}$.

\subsection{Scanning Electron Microscopy (SEM)}

Results obtained using the Scanning Electron Microscopy for carbon steel samples after immersion of $3 \mathrm{~h}$ in $0.5 \mathrm{~mol}$ $\mathrm{L}^{-1} \mathrm{HCl}$, in the presence and the absence (Blank) of PVP 40000 (at the concentration of $1.0 \times 10^{-7} \mathrm{~mol} \mathrm{~L}^{-1}$ ), can be observed in Figure 8.

The formation of pitting corrosion was clearly observed on the carbon steel surface in both cases, probably due to the presence of chloride ions ${ }^{12}$. However, pitting corrosion was attenuated in the presence of PVP, which might be related to the adsorption of the organic inhibitor on the surface that blocks the metal sites, thus avoiding chloride adsorption, and consequently, inhibiting pitting corrosion formation ${ }^{16,24}$.

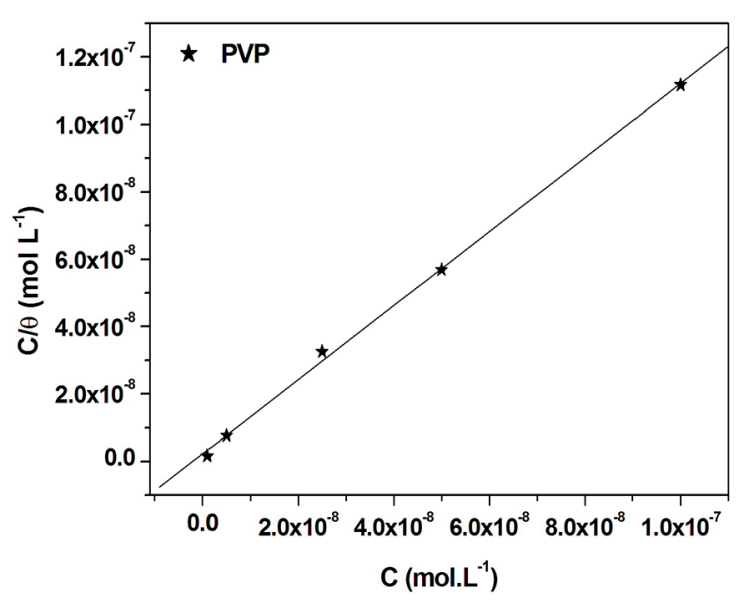

Figure 7. Langmuir isotherm plot for the adsorption of PVP on carbon steel surface in $\mathrm{HCl} 0.5 \mathrm{~mol} \mathrm{~L}^{-1}$.

Table 3. Electrochemical Impedance data for carbon steel in $0.5 \mathrm{~mol} \mathrm{~L}^{-1} \mathrm{HCl}$, at different PVP concentrations.

\begin{tabular}{lcccccccccc}
\hline Inhibitors & $\begin{array}{c}C \text { inh }(\mathrm{mol} \\
\left.\mathrm{L}^{-1}\right)\end{array}$ & $\begin{array}{c}\mathrm{OCP} / \mathrm{Ag} / \\
\mathrm{AgCl} \\
(\mathrm{mV})\end{array}$ & $\boldsymbol{R}_{\mathrm{ct}}\left(\Omega \mathrm{cm}^{2}\right)$ & $n$ & $\begin{array}{c}\boldsymbol{Y}_{0}(\mu \mathrm{Mho} \\
\left.\mathrm{cm}^{-2}\right)\end{array}$ & $\boldsymbol{f}_{\text {max }}(\mathrm{Hz})$ & $\begin{array}{c}\boldsymbol{C}_{\mathrm{dl}}(\mu \mathrm{F} \\
\left.\mathrm{cm}^{-2}\right)\end{array}$ & $\boldsymbol{\theta}$ & $\boldsymbol{I}_{\mathrm{EIS}}(\%)$ \\
\hline Blank & - & -460 & 120.65 & 0.776 & 221 & 13.89 & 81.21 & - & - \\
& $1.0 \times 10^{-9}$ & -463 & 304.24 & 0.819 & 143 & 5.42 & 75.49 & 0.6034 & 60 \\
& $5.0 \times 10^{-9}$ & -459 & 353.93 & 0.807 & 150 & 4.29 & 79.42 & 0.6591 & 66 \\
PVP & $2.5 \times 10^{-8}$ & -444 & 378.95 & 0.778 & 175 & 5.42 & 79.97 & 0.6816 & 68 \\
& $5.0 \times 10^{-8}$ & -423 & 999.08 & 0.777 & 126 & 1.67 & 74.54 & 0.8792 & 88 \\
& $1.0 \times 10^{-7}$ & -422 & 1156.46 & 0.781 & 93 & 1.67 & 55.54 & 0.8957 & 90 \\
\hline
\end{tabular}




\subsection{Comparison with literature data}

The results of PVP 40000 inhibition efficiency obtained in this study were confronted with data-related literature to verify their relevance. Literature data were compiled and can be seen in Table 4 .
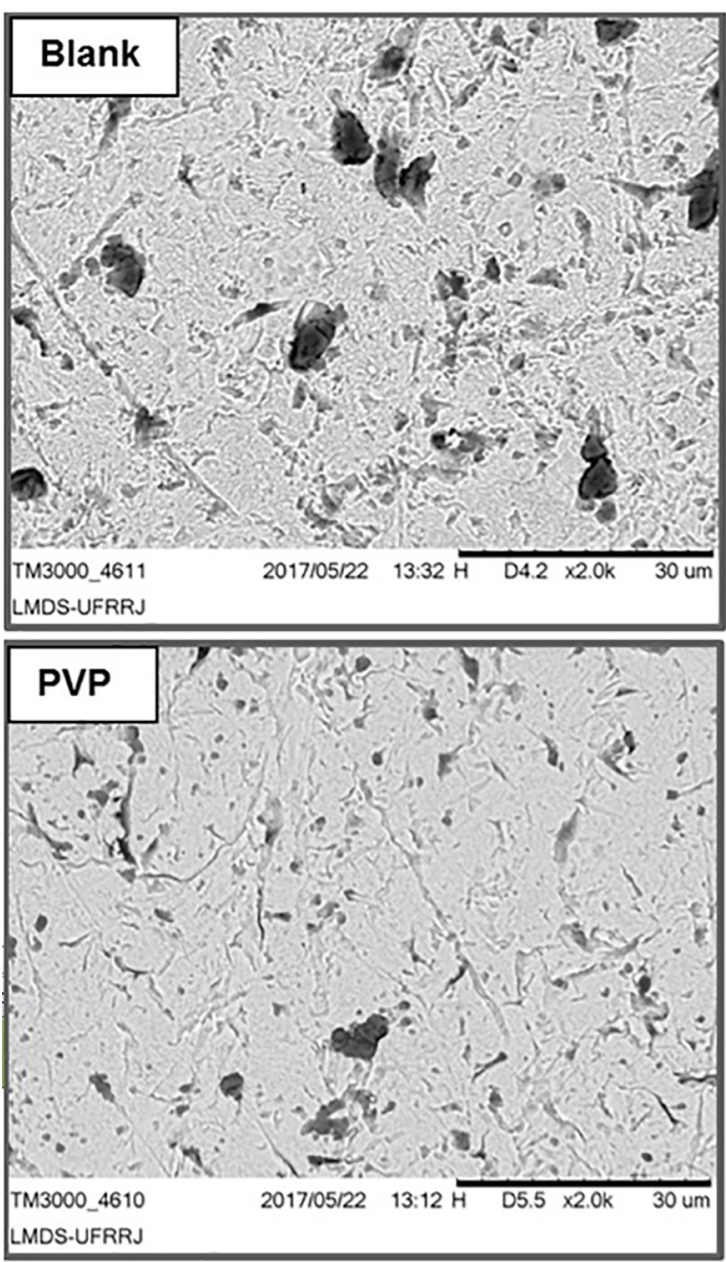

Figure 8. SEM micrograph $(2000 x)$ of carbon steel immersed in $0.5 \mathrm{~mol} \mathrm{~L}^{-1} \mathrm{HCl}$, in the absence (Blank) and the presence of $1.0 \times 10^{-7} \mathrm{~mol} \mathrm{~L}^{-1} \mathrm{PVP}$.
The maximum inhibition efficiency value obtained in this work was $90 \%$, by EIS, using $1.0 \times 10^{-7} \mathrm{~mol} \mathrm{~L}^{-1} \mathrm{PVP}$ 40000 in $0.5 \mathrm{~mol} \mathrm{~L}^{-1} \mathrm{HCl}$. No studies with PVP 40000 had been found in literature before; however, it is noticeable that at small concentration, PVP 40000 shows higher inhibition efficiency when compared with the ones reported in literature even though they are under distinct conditions $2,4,8,10$.

\section{Conclusion}

PVP 40000 acted as a good corrosion inhibitor of AISI 1020 carbon steel in $\mathrm{HCl} 0.5 \mathrm{~mol} \mathrm{~L}^{-1}$, showing maximum efficiencies of $90 \%$ and $89 \%$ at low concentration $\left(1.0 \times 10^{-7}\right.$ mol L $\left.{ }^{-1}\right)$, measured by LPR and EIS, respectively. A semicircle increase was observed in Nyquist plots when the inhibitor concentration rises. PP curves showed that PVP 40000 can be classified as a mixed inhibitor shifting to the anodic region. The adsorption on metal surface was in accordance with the Langmuir adsorption isotherm.

\section{Acknowledgements}

The authors are very grateful to CAPES (Coordenação de Aperfeiçoamento de Pessoal de Nível Superior), CNPq (Conselho Nacional de Desenvolvimento Científico e Tecnológico) and Petrobras (Petróleo Brasileiro S. A.), as well as to P\&D ANEEL-SUPERCABO project, for financial support.

\section{References}

1. Al Juhaiman LA, Mustafa AA, Mekhamer WK. Polyvinyl Pyrrolidone as a Green Corrosion Inhibitor of Carbon Steel in Neutral Solutions Containing $\mathrm{NaCl}$ : Electrochemical and Thermodynamic Study. International Journal of Electrochemical Science. 2012;7:8578-8596.

2. Ban C, He Y, Shao X, Wang Z. Effects of polymer corrosion inhibitor on widening etch tunnels of aluminium foil for capacitor. Corrosion Science. 2014;78:7-12.

Table 4.. Experimental data of inhibition efficiency, corrosive medium, concentration, metal-type and technique reported in literature about the PVP polymer.

\begin{tabular}{|c|c|c|c|c|c|c|}
\hline PVP & Corrosive Agent & $\mathrm{C}_{\mathrm{inh}}\left(\mathrm{mol} \mathrm{L}^{-1}\right)$ & Alloy & Technique & $I E(\%)$ & Reference \\
\hline PVP 8000 & $0.1 \mathrm{~mol} \mathrm{~L}^{-1} \mathrm{NaCl}$ & $2.5 \times 10^{-4}$ & Carbon steel & EIS PP & 36.544 .0 & 2 \\
\hline PVP 8000 & $2 \mathrm{~mol} \mathrm{~L}^{-1} \mathrm{HCl}$ & $1.0 \times 10^{-3}$ & Carbon steel & EIS PP & 86.589 .5 & 4 \\
\hline PVP 10000 & $7 \mathrm{~mol} \mathrm{~L}^{-1} \mathrm{H}_{3} \mathrm{PO}_{4}$ & $5.0 \times 10^{-5}$ & Carbon steel & Mass loss & 89.0 & 8 \\
\hline PVP 10000 & $\begin{array}{c}\text { Water }+1 \mathrm{mg} \mathrm{L}^{-1} \mathrm{FeCl}_{3}+\text { drops } \\
\text { of } \mathrm{H}_{2} \mathrm{SO}_{4} \text { and }\end{array}$ & $1.0 \times 10^{-2}$ & 316L Stainless steel & PP & 42.7 & 9 \\
\hline PVP 45000 & $\begin{array}{l}\text { Water + } 1 \mathrm{mg} \mathrm{L}^{-1} \mathrm{FeCl}_{3}+\text { drops } \\
\text { of } \mathrm{H}_{2} \mathrm{SO}_{4}\end{array}$ & $1.0 \times 10^{-2}$ & 316L Stainless steel & PP & 96.9 & 9 \\
\hline PVP 44000 & $0.5 \mathrm{~mol} \mathrm{~L}^{-1} \mathrm{H}_{2} \mathrm{SO}_{4}$ & $1.0 \times 10^{-4}$ & Carbon steel & Mass loss & 67.0 & 10 \\
\hline PVP 40000 & $0.5 \mathrm{~mol} \mathrm{~L}^{-1} \mathrm{HCl}$ & $1.0 \times 10^{-7}$ & AISI 1020 Carbon steel & EIS LRP PP & $\begin{array}{c}90.089 .0 \\
89.0\end{array}$ & This study \\
\hline
\end{tabular}


3. Umoren SA. Corrosion inhibition of aluminum alloy $3 \mathrm{SR}$ in $\mathrm{HCl}$ by polyvinylpyrrolidone and polyacrylamide: Effect of molecular structure on inhibition efficiency. Surface Review and Letters. 2009;16(6):831-844.

4. Al Juhaiman LA. Polyvinyl pyrrolidone as a Corrosion Inhibitor for Carbon Steel in HCl. International Journal of Electrochemical Science. 2016;11:2247-2262.

5. Umoren SA, Eduok UM. Application of carbohydrate polymers as corrosion inhibitors for metal substrates in different media: A review. Carbohydrate Polymers. 2016;140:314-341.

6. Karthikaiselvi R, Subhashini S. The water soluble composite poly(vinylpyrrolidone-methylaniline): A new class of corrosion inhibitors of mild steel in hydrochloric acid media. Arabian Journal of Chemistry. 2017;10(Suppl. 1):S627-S635.

7. Mostafa AEKB, Abdel-Wahaab SM, Mabrouk ESM. The corrosion behaviour of zinc metal in acidic solutions of polyvinylpyrrolidones and polyvinylpyridines. Surface and Coatings Technology. 1986;27(4):317-324.

8. Jtanguo Y, Lin W, Otieno-Alego V, Schweinsberg DP. Polyvinylpyrrolidone and polyethylenimine as inhibitors for the corrosion of a low carbon steel in phosphoric acid. Corrosion Science. 1995;37(6):975-985.

9. Khaled MM. The effect of molecular weight on the corrosion protection properties of polyvinylpyrrolidone polymers on stainless steel. Arabian Journal for Science and Engineering. 2010;35(1A):29-39.

10. Umoren SA. Synergistic inhibition effect of polyethylene glycol-polyvinyl pyrrolidone blends for mild steel corrosion in sulphuric acid medium. Journal of Applied Polymer Science. 2011;119(4):2072-2084.

11. Goulart CM, Esteves-Souza A, Martinez-Huitle CA, Rodrigues CJF, Maciel MAM, Echevarria A. Experimental and theoretical evaluation of semicarbazones and thiosemicarbazones as organic corrosion inhibitors. Corrosion Science. 2013;67:281291.

12. Ansari KR, Quraishi MA, Singh A. Schiff's base of pyridyl substituted triazoles as new and effective corrosion inhibitors for mild steel in hydrochloric acid solution. Corrosion Science. 2014;79:5-15.

13. Ituen E, James A, Akaranta O, Sun S. Eco-friendly corrosion inhibitor from Pennisetum purpureum biomass and synergistic intensifiers for mild steel. Chinese Journal of Chemical Engineering. 2016;24(10):1442-1447.
14. Mishra M, Tiwari K, Singh AK, Singh VP. Versatile coordination behaviour of a multi-dentate Schiff base with manganese(II), copper(II) and zinc(II) ions and their corrosion inhibition study. Inorganica Chimica Acta. 2015;425:36-45.

15. Ansari KR, Quraishi MA. Bis-Schiff bases of isatin as new and environmentally benign corrosion inhibitor for mild steel. Journal of Industrial and Engineering Chemistry. 2014;20(5):2819-2829.

16. Valbon A, Neves MA, Echevarria A. Experimental and Theoretical Evaluation of Asymmetric Thioureas on the Corrosion of Carbon Steel in Acidic Medium. International Journal of Electrochemical Science. 2017;12:3072-3087.

17. Xu B, Ji Y, Zhang X, Jin X, Yang W, Chen Y. Experimental and theoretical studies on the corrosion inhibition performance of 4-amino-N,N-di- (2-pyridylmethyl)-aniline on mild steel in hydrochloric acid. RSC Advances. 2015;5(69):56049-56059.

18. Hegazy MA, Aiad I. 1-Dodecyl-4-(((3-morpholinopropyl)imino) methyl)pyridine-1-ium bromide as a novel corrosion inhibitor for carbon steel during phosphoric acid production. Journal of Industrial and Engineering Chemistry. 2015;31:91-99.

19. Torres VV, Rayol VA, Magalhães M, Viana GM, Aguiar LCS, Machado SP, et al. Study of thioureas derivatives synthesized from a green route as corrosion inhibitors for mild steel in $\mathrm{HCl}$ solution. Corrosion Science. 2014;79:108-118.

20. El-Lateef HMA. Experimental and computational investigation on the corrosion inhibition characteristics of mild steel by some novel synthesized imines in hydrochloric acid solutions. Corrosion Science. 2015;92:104-117.

21. Albuquerque MA, de Oliveira MCC, Echevarria A. Anticorrosive Activity of 2-Hydroxybenzaldehyde-thiosemicarbazone for AISI 1020 Carbon Steel in Acid Medium. International Journal of Electrochemical Science. 2017;12:852-860.

22. Ahamad I, Prasad R, Quraishi MA. Thermodynamic, electrochemical and quantum chemical investigation of some Schiff bases as corrosion inhibitors for mild steel in hydrochloric acid solutions. Corrosion Science. 2010;52(3):933-942.

23. Behpour M, Ghoreishi SM, Mohammadi N, Soltani N, SalavatiNiasari M. Investigation of some Schiff base compounds containing disulfide bond as $\mathrm{HCl}$ corrosion inhibitors for mild steel. Corrosion Science. 2010;52(12):4046-4057.

24. Biswas A, Pal S, Udayabhanu G. Experimental and theoretical studies of xanthan gum and its graft co-polymer as corrosion inhibitor for mild steel in $15 \% \mathrm{HCl}$. Applied Surface Science. 2015;353:173-183. 